\title{
Dental Office Prevention of Coronavirus Infection
}

\author{
Cesare D’Amico ${ }^{1, *} \quad$ Salvatore Bocchieri, ${ }^{2, *} \quad$ Rosa De Stefano ${ }^{1} \quad$ Francesca Gorassini $^{1}$ \\ Giovanni Surace ${ }^{3}$ Giulia Amoroso ${ }^{1}$ Cristina Scoglio ${ }^{1}$ Roberta Mastroieni ${ }^{1}$ Dario Gambino ${ }^{1}$ \\ Emanuele Mario Amantia ${ }^{1}$ Stefania Marino ${ }^{1}$ Chiara Stumpo ${ }^{1}$ Luca Fiorillo ${ }^{1, \odot}$
}

${ }^{1}$ Department of Biomedical and Dental Sciences, Morphological and Functional Images, University of Messina, Messina, Italy

2Department of Medicine and Surgery, School of Medicine, University of Insubria, Varese, Italy

${ }^{3}$ Clinical Analysis Laboratory "Dott. Francesco Siracusa Rizzi s.r.l.," Reggio Calabria, Italy

\begin{abstract}
Address for correspondence Luca Fiorillo, DDS, MSc, PhD, Department of Biomedical and Dental Sciences, Morphological and Functional Images, University of Messina, Via Consolare Valeria 1, Messina 98100, Italy (e-mail: Ifiorillo@unime.it).

Rosa De Stefano, Psy, PsyT, Department of Biomedical and Dental Sciences, Morphological and Functional Images, University of Messina, Via Consolare Valeria 1, Messina 98100, Italy (e-mail: rsdestefano@libero.it).
\end{abstract}
Abstract
Keywords
- coronavirus disease 2019
- infection risk
- public health
- dental office
- virus

Coronavirus disease is now spreading in different countries of the world. The alarmism created through the media also creates confusion in people about virus spreading. The health care environments among which the dental practice could be places of spread of the virus, especially places where patients with systemic pathology could be exposed to this. The purpose of this article is to clarify coronavirus disease 2019 and its management in the dental practice. Only by following the normal guidelines on disinfection and sterilization of environments and operators, with some additional rules on the management of patients in the waiting room, it is possible to limit this risk. Limiting the risk of spreading the virus is one of the keys to its eradication.

\section{Introduction}

Coronavirus disease 2019 (COVID-19) or acute respiratory disease from severe acute respiratory syndrome coronavirus 2 (SARS-CoV-2) is an infectious respiratory disease caused by the virus called SARS-CoV-2 belonging to the coronavirus family. The first cases were found during the SARS-CoV-2 epidemic of 2019 to 2020. The responsible virus is believed to be of zoonotic origin, but by February 2020 the predominant mode of transmission results from man to man, generally through infected water and mucus particles (droplets) that people release by sneezing or coughing and which are then inspired by other people. Coronavirus mainly affects the lower respiratory tract and causes several symptoms described as flu-like. ${ }^{1-7}$ It is transmitted mainly through close and prolonged contacts from man to man. The main symptoms are fever, cough,

*Authors contributed equally to this study.

DOI https://doi.org/ 10.1055/s-0040-1715923 ISSN 1305-7456. breathing difficulties, muscle pain, and sore throat. It has only been known for a few weeks and scientific reports on its clinical evolution knowledge are constantly updated. Currently, rapid testing is taking place with the help of nasopharyngeal, oropharyngeal swab, bronchoalveolar lavage, sputum, urine, and blood. ${ }^{8}$ The purpose of this study is to summarize all the necessary information concerning the diffusion methods of COVID-19 and clarify the behaviors to be used.

\section{Materials and Methods}

The term personal protective equipment (PPE) refers to products that have the function of protecting the person who wears them from risks to health and safety. These devices are used in many areas, including in the workplace, home, sports, and recreation. PPE to protect the respiratory tract are used to protect against potentially harmful aeriform substances (gas, dust, and vapors) and to allow normal breathing when

(c) 2020. European Journal of Dentistry.

This is an open access article published by Thieme under the terms of the Creative Commons Attribution-NonDerivative-NonCommercial-License, permitting copying and reproduction so long as the original work is given appropriate credit. Contents may not be used for commercial purposes, or adapted, remixed, transformed or built upon. (https://creativecommons.org/ licenses/by-nc-nd/4.0/)

Thieme Medical and Scientific Publishers Pvt. Ltd. A-12, 2nd Floor, Sector 2, Noida-201301 UP, India 
the oxygen level is in any case higher than the limit value of $17 \%$. They are classified as following ${ }^{9-11}$ :

- Filter: as masks

- Insulators: open or closed circuit. The filters can also be classified as dustproof, antigas, or combined ( - Figs. 1, 2).

Eye protection devices are also different. The eyes are subject to various risks: splinters, hot or caustic or corrosive materials, and radiation, which can lead to three types of injuries: mechanical, optical, and thermal. To protect these delicate organs, the types of PPE are used:

- Glasses

- Masks

- Visors

- Screens

They too may or may not be equipped with a filter.

The devices for the protection of the upper limbs, particularly the hands are most exposed to risks, which can be of various kinds:

- Gloves

- Mechanical and electrostatic risks

- Electrical risks/electrocution

- Chemical and microbiological risks

- Cold risks

- Risks from heat and fire

- Risks from vibrations

- Security personal digital assistants

- Paramanic and super-sleeved

The gloves can be of different materials: latex, nitrile, and vinyl. ${ }^{12,13}$

\section{Results}

From the research performed in the literature, it is possible to summarize the guidelines for limiting and avoiding the risk of COVID-19 contagion in dental office. Here are some rules to be applied to patients to limit the risks of contagion once they arrive in the dentist's office:

- Before the patient has access to the dental office, it is mandatory to carry out a telephone triage to verify the total absence of symptoms potentially attributable to the infection by coronavirus SARS-CoV-2 such as cough, conjunctivitis, fever (even modest), sneezing, rhinitis, diarrhea, etc., and to ask for any transfers, personal trips, and/or contacts with people from areas of maximum contagion (see questionnaire). In the event of a positive answer to these questions, it should be evaluated-depending on the possible severity of the dental problem to be treated-to receive the patient at the end of the working day. Should the patient go to the office without an appointment? The secretarial staff will have to ask these same questions before the person has access to the operating areas of the study. ${ }^{14-18}$

- Avoid having multiple patients in the waiting room. Mandatory to maintain the recommended distance of at least $1.5 \mathrm{~m}$ between a person and the nearest one. Better to arrange appointments to have only one patient at a time in the waiting room.

- Before having access to the operating area, the patient should have personal belongings (bags, telephones, and others) with them, the assistance staff or secretary of the office must provide a disposable bag in which to place all the objects they own at the end of the treatment session, and the patient will take care of carrying them without removing them from the container provided. It is preferable to carry out any accounting operations before the patient is invited to put his personal items in the disposable container. Before entering the operating area, the patient should be invited to wash their hands thoroughly for at least 20 seconds with specific soaps. Any further hand treatments with hydroalcoholic or chlorine-based gels are useful.

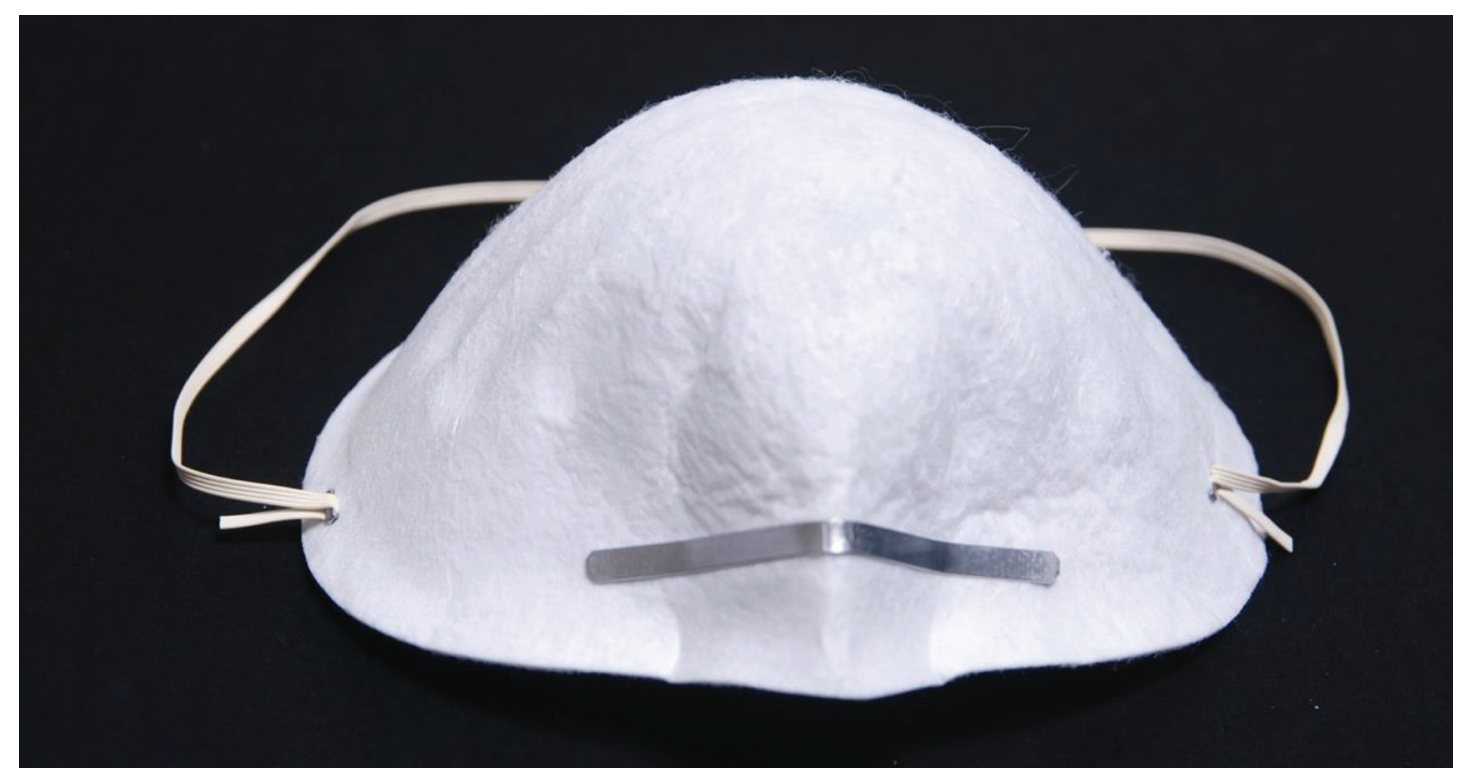

Fig. 1 Filter mask (http://fotoedukacja.edu.pl, CC BY-SA 3.0). 


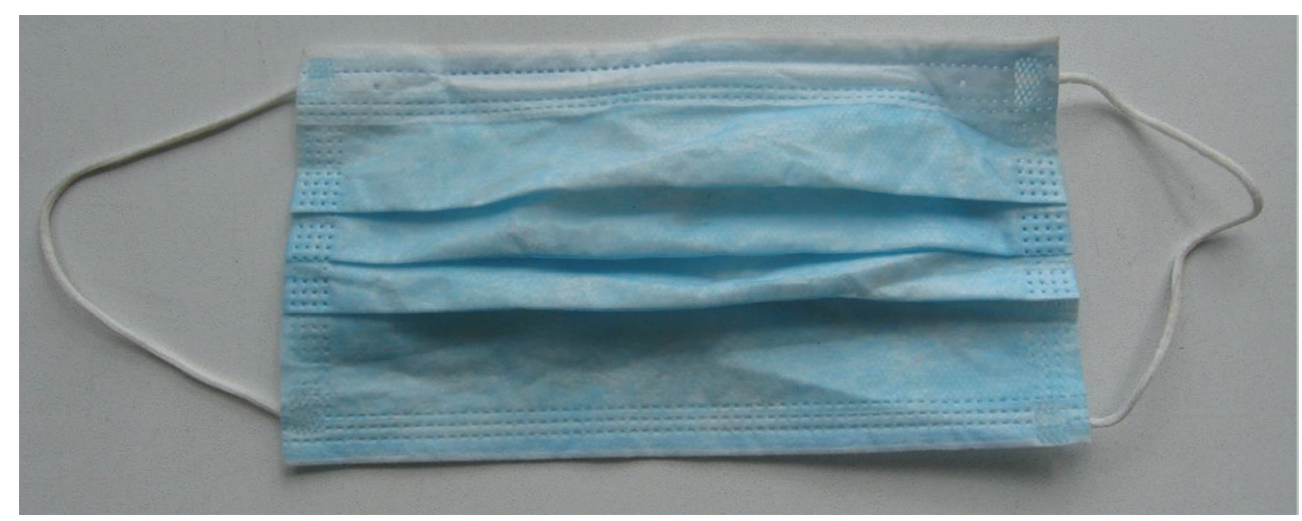

Fig. 2 Common dental office surgical mask (CC0).

- Make sure that during their stay, patients do not touch anything in the office, including door handles, surfaces, objects, etc. The secretarial accounting operations (payments, scheduling appointments, etc.) must be managed by staff of PPE. The gloves must be changed for each patient.

- All study staff must always wear PPE (double pair of gloves, nonwoven headgear, and suitable mask-the type of mask to be used varies according to the patient to be treated, the type of performance, and the geographical area in which the dental office is located), disposable socks, and shirts. Before putting on disposable gloves, wash your hands thoroughly for at least 20 seconds with specific soaps and/ or hydroalcoholic or chlorine-based gels. ${ }^{19}$ Only FFP2 and 3 masks guarantee real protection from the risk of inhalation of the virus. If you find yourself operating in the red zone or on patients with suspected or confirmed infection, the operator will need to use FFP3 masks; the only ones capable of protecting against the risk of contagion linked to the aerosol that is formed during use of water spray instruments (micromotor, turbine, ultrasound, air flow, etc.)..$^{20,21}$

- Frequently and for a long time to change the air between one patient and another in operational studies and in the waiting room.

- Scrupulously clean all study surfaces when changing each patient with hydroalcoholic (70\% ethyl alcohol) or chlorine-based disinfectants ( $0.1 \%$ sodium hypochlorite solutions), with particular attention to the dental unit and all surfaces with whom the patient came into contact (waiting chairs, reception desk, etc.). Surface disinfection could be performed with $0.1 \%$ sodium hypochlorite or 62 to $71 \%$ ethanol for 1 minute. ${ }^{22}$ The most exposed surfaces will be protected with disposable barriers which, at the end of the session, must be replaced, disposing of them in special waste.

- Instruct staff on how to wear, remove, and properly dispose of used PPE. The gloves must also be worn double, as can be recommended for masks, if they are normal masks. When the PPE are removed, a precise procedure must be followed: first of all, remove the first pair of gloves, then the gown, the cap, the shoes, and the masks. Finally, the glasses and protective screens, which will be cleaned with specific disinfectants. Finally, remove the second pair of gloves. All disposable personal protective equipment used will be disposed of as potentially infectious special waste.

- Rinse the patient's mouth with a $1 \%$ solution of hydrogen peroxide for 30 seconds or with 0.2 to $0.3 \%$ chlorhexidine to reduce the bacterial/viral load. It is strongly recommended to apply the rubber dam and use double suction.

- Remove all potential contaminants from the waiting room (toys, consoles, newspapers, books, brochures, etc.).

Dental patients and professionals can be exposed to pathogenic microorganisms, including viruses and bacteria that infect the oral cavity and respiratory tract. ${ }^{23,24}$ Dental care settings invariably carry the risk of 2019-nCoV infection due to the specificity of its procedures, which involves face-to-face communication with patients, and frequent exposure to saliva, blood, and other body fluids, and the handling of sharp instruments ( - Fig. 3). ${ }^{25}$ Since today patients can no longer attend the dentist with the usual habit (unless urgent needs), it is necessary to maintain a high standard of oral hygiene with the constant use of a toothbrush, toothpaste, and bottle brush. The scientific community is therefore urged to spread this useful message.

\section{Discussion}

Certainly, these guidelines do not represent a novelty in the medical field, and indeed reflect common standards of good conduct to be used in health care facilities. Some of the places most at risk are precisely hospitals, medical, and dental offices. Some effective generic prevention methods in medical structure are ${ }^{14,26-31}$ :

- Always change the air between one patient and another and periodically also in the waiting room.

- Constantly use PPE while you are working and demand maximum attention in the use of PPE by medical and health care personnel (- Figs. 1, 2).

- Wash your hands for at least 20 seconds. The washing operation must be preliminary to the use of the disinfectant. 


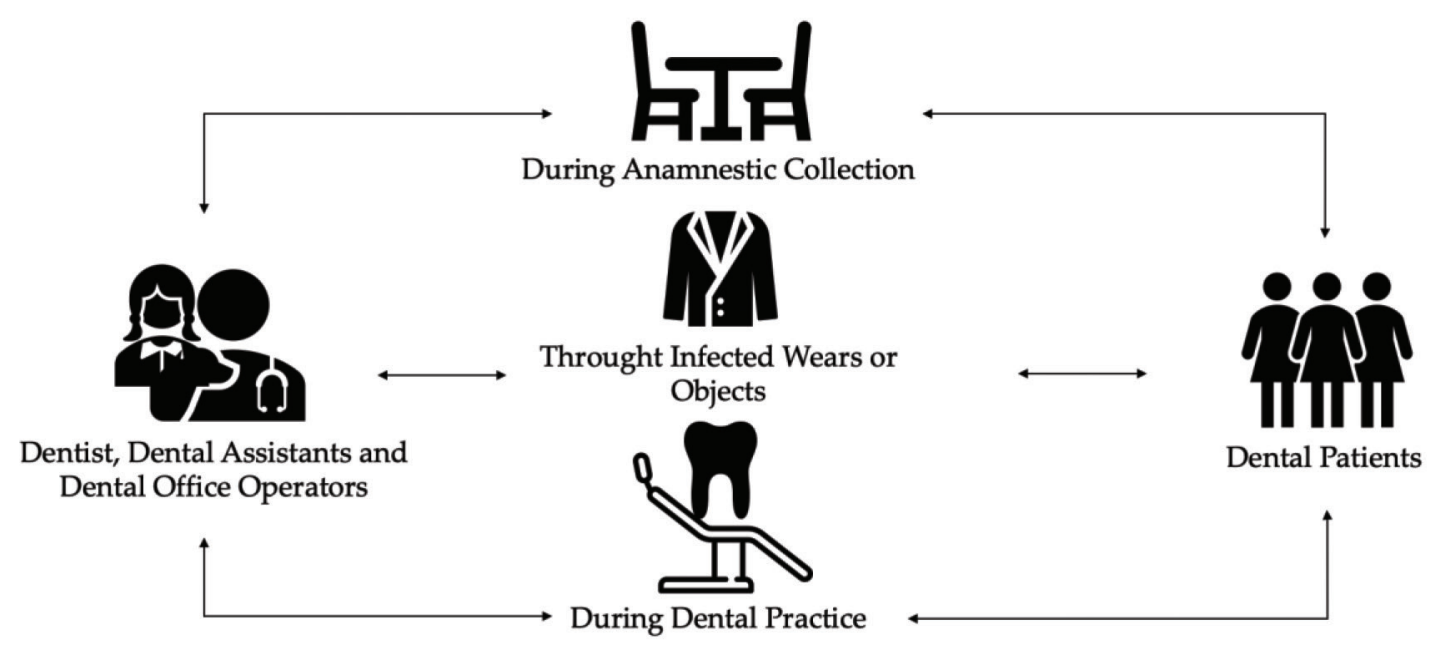

Fig. 3 Common dental office coronavirus disease 2019 transmission routes.

- Clean the clinical contact surfaces (the surfaces that touch each other more frequently such as the buttons and handles) always between each patient and protect them with devices to be changed every time between the patients. The virus can reach surfaces in the form of an aerosol. Therefore, following nebulization through people (sneezing or coughing) or electromedical machinery, infection via surfaces should be considered, since the latter could remain viable and infectious for hours or days. $^{22}$

- Make an alcoholic disinfectant available to patients and careers at the entrance and invite them to clean their hands before sitting down.

These are the indications for the prevention of COVID-2019 infection that are considered "more effective without incurring unnecessary and even dangerous alarms." ${ }^{6,7}$ The common transmission routes of novel coronavirus include direct transmission (cough, sneeze, and droplet inhalation transmission) and contact transmission (contact with oral, nasal, and eye mucous membranes). Although common clinical manifestations of novel coronavirus infection do not include eye symptoms, the analysis of conjunctival samples from confirmed and suspected cases of 2019-nCoV suggests that the transmission of 2019-nCoV is not limited to the respiratory tract, and that eye exposure may provide an effective way for the virus to enter the body (-Fig. 3). ${ }^{12,32-34}$

In some European countries, all industry associations and trade unions suggest the temporary closure of dental practices to limit the spread of the virus. Since the dental practice is a high-risk place, as it is in contact with saliva, and possibly forms of aerosols generated by dental instruments. ${ }^{35}$ Furthermore, these forms of aerosol cannot be blocked by the common surgical masks used in dentistry (-Fig. 2). The treatments and dental surgeries must be reserved for acute pain, infections such as a gingival abscess, trauma, or the results of accidental events are some examples of clinical conditions which are of an urgent nature and which must be capable of being treated.
In addition, if the patient is at a greater risk of contracting infection or has symptoms attributable to COVID-19 infection or is also in quarantine, treatment will need to be postponed to a later period. Attention to coronavirus and the prevention measures adopted in some regions are triggering forms of collective psychosis that could also affect the dental practice, erroneously seen as a possible "place of spread of the virus". 1,34,36,37 The difficulty to practice physical activity adds to the risks associated with sedentary habits, maintaining exercise routine even at home, are needed to avoid the consequences of inactivity. ${ }^{38,39}$

Like all health care facilities, the dental practice is already equipped, the trained staff and the normal sterilization and disinfection protocols protect us operators, and our patients from far more serious infections. ${ }^{40-47}$

The test to check coronavirus positivity also does not detect those who came into contact with the virus and who did not manifest the infection. It only detects positivity at the precise moment it is made. This is why II level tests have been performed to evaluate the presence of antibodies, which are evidence of the past presence of the virus. ${ }^{28}$

There is still no defined therapy or therapeutic protocol. In cases where the disease is more advanced, the hospital treatment aimed at supporting vital functions, such as artificial ventilation or extra corporeal membrane oxygenation. It is important for the community to be able to contain the number of infected patients as much as possible while avoiding to create alarmism among the population. . $^{3,48-53}$

\section{Conclusion}

The dental office could be a place where even debilitated patients are exposed to this risk. For this reason, following the guidelines and the strictest protocols for the disinfection of operators and environments is essential. If the number of infected decreases, hospital facilities will be freed from this excessive workload, and at the same time, the healing and immunization of other individuals may lead to the eradication of this pandemic. 


\section{Note}

All authors have read and agreed to the published version of the manuscript.

\section{Authors' Contributions}

C.D.A. and S.B. dedicated to conceptualization and methodology. R.D.S., F.G., R.M., S.M., and C.S. focused on investigation, resources, data curation, writing-original draft preparation, writing-review, and editing. G.S., G.A., C.S., D.G., and E.M.A supported in visualization. L.F. helped in project administration.

\section{Conflict of Interest}

None declared.

\section{References}

1 Li JO, Lam DSC, Chen Y, Ting DSW. Novel coronavirus disease 2019 (COVID-19): the importance of recognising possible early ocular manifestation and using protective eyewear. $\mathrm{Br} \mathrm{J}$ Ophthalmol 2020;104(3):297-298

2 Jalava K. First respiratory transmitted food borne outbreak? Int J Hyg Environ Health 2020;226:113490

3 Gostic K, Gomez ACR, Mummah RO, Kucharski AJ, Lloyd-Smith JO. Estimated effectiveness of symptom and risk screening to prevent the spread of COVID-19. eLife 2020;9:e55570

4 Gilbert M, Pullano G, Pinotti F, et al. Preparedness and vulnerability of African countries against importations of COVID-19: a modelling study. Lancet 2020;395(10227):871-877

5 Dong E, Du H, Gardner L. An interactive web-based dashboard to track COVID-19 in real time. Lancet Infect Dis 2020;20(5):533-534

6 Calisher C, Carroll D, Colwell R, et al. Statement in support of the scientists, public health professionals, and medical professionals of China combatting COVID-19. Lancet 2020;395(10226):e42-e43

7 Aw J. The non-contact handheld cutaneous infra-red thermometer for fever screening during the COVID-19 global emergency. J Hosp Infect 2020;104(4):451

8 Hamid H, Khurshid Z, Adanir N, Zafar MS, Zohaib S. COVID19 pandemic and role of human saliva as a testing biofluid in point-of-care technology 2020. Eur J Dent 2020;14(suppl S1):S123-S129 doi:10.1055/s-0040-1713020

9 McGoldrick M. Personal protective equipment: protecting the eyes. Home Healthc Now 2019;37(4):234-235

10 McGoldrick M. Personal protective equipment. Home Healthc Now 2015;33(2):112-113

11 Honda H, Iwata K. Personal protective equipment and improving compliance among healthcare workers in high-risk settings. Curr Opin Infect Dis 2016;29(4):400-406

12 Wax RS, Christian MD. Practical recommendations for critical care and anesthesiology teams caring for novel coronavirus (2019-nCoV) patients. Can J Anaesth 2020;67(5):568-576

13 Wang X, Zhang X, He J. Challenges to the system of reserve medical supplies for public health emergencies: reflections on the outbreak of the severe acute respiratory syndrome coronavirus 2 (SARS-CoV-2) epidemic in China. Biosci Trends 2020;14(1):3-8

14 The Lancet. COVID-19: fighting panic with information. Lancet 2020;395(10224):537 doi:10.1016/S0140-6736(20)30379-2

15 Spagnuolo G, De Vito D, Rengo S, Tatullo M. COVID-19 outbreak: an overview on dentistry. Int J Environ Res Public Health 2020;17(6):2094

16 Mascitti M, Campisi G. Dental public health landscape: challenges, technological innovation and opportunities in the $21 \mathrm{st}$ century and COVID-19 pandemic. Int J Environ Res Public Health 2020;17(10):3636

17 Giudice A, Barone S, Muraca D, et al. Can teledentistry improve the monitoring of patients during the COVID-19 dissemination? A descriptive pilot study. Int J Environ Res Public Health 2020;17(10):3399

18 Cervino G, Oteri G. COVID-19 pandemic and telephone triage before attending medical office: problem or opportunity? Medicina (Kaunas) 2020;56(5):250

19 Fiorillo L. Chlorhexidine gel use in the oral district: a systematic review. Gels 2019;5(2):31

20 Fiorillo L, Leanza T, Worldwide 3D printers against the new coronavirus. Prosthesis 2020;2(2):87-90 doi:10.3390/ prosthesis2020009.

21 Cavallo L, Marcianò A, Cicciù M, Oteri G. 3D printing beyond dentistry during COVID 19 epidemic: a technical note for producing connectors to breathing devices. Prosthesis 2020;2(2):46-52

22 Fiorillo L, Cervino G, Matarese M, et al. COVID-19 surface persistence: a recent data summary and its importance for medical and dental settings. Int J Environ Res Public Health 2020;17(9):3132

23 Yildirim S, Yildiz E, Kubar A. TaqMan real-time quantification of Epstein-Barr Virus in severe early childhood caries. Eur J Dent 2010;4(1):28-33

24 Muralidharan S, Acharya A, Margabandhu S. Dentition status and treatment needs of human immunodeficiency virus-positive patients on anti retro viral therapy in Raichur taluk, Karnataka, India: a cross sectional study. Eur J Dent 2017; 11(2):238-241

25 World Health O. Infection prevention and control during health care for probable or confirmed cases of Middle East respiratory syndrome coronavirus (MERS-CoV) infection: interim guidance: updated October 2019. Available at: https:// extranet.who.int/iris/restricted/handle/10665/174652. Accessed 2019

26 Tetro JA. Is COVID-19 receiving ADE from other coronaviruses? Microbes Infect 2020;22(2):72-73

27 Song P, Karako T. COVID-19: real-time dissemination of scientific information to fight a public health emergency of international concern. Biosci Trends 2020;14(1):1-2

28 Qin C, Liu F, Yen TC, Lan X. 18F-FDG PET/CT findings of COVID19: a series of four highly suspected cases. Eur J Nucl Med Mol Imaging 2020;47(5):1281-1286

29 Phan T. Genetic diversity and evolution of SARS-CoV-2. Infect Genet Evol 2020;81:104260

30 Peeri NC, Shrestha N, Rahman MS, et al. The SARS, MERS and novel coronavirus (COVID-19) epidemics, the newest and biggest global health threats: what lessons have we learned?. Int J Epidemiol 2020;49(3):717-726 doi:10.1093/ije/dyaa033

31 Ling L, Joynt GM, Lipman J, Constantin JM, Joannes-Boyau O. COVID-19: a critical care perspective informed by lessons learnt from other viral epidemics. Anaesth Crit Care Pain Med 2020;39(2):163-166

32 Peng X, Xu X, Li Y, Cheng L, Zhou X, Ren B. Transmission routes of 2019-nCoV and controls in dental practice. Int J Oral Sci 2020;12(1):9

33 Nastro E, Musolino C,Allegra A, et al.Bisphosphonate-associated osteonecrosis of the jaw in patients with multiple myeloma and breast cancer. Acta Haematol 2007;117(3):181-187

34 Cicciù M, Risitano G, Lo Giudice G, Bramanti E. Periodontal health and caries prevalence evaluation in patients affected by Parkinson's disease. Parkinsons Dis 2012;2012:541908

35 Alwan NA, Bhopal R, Burgess RA, et al; 36 signatories. Evidence informing the UK's COVID-19 public health response must be transparent. Lancet 2020;395(10229) :1036-1037

36 Xu B, Kraemer MUG; Open COVID-19 Data Curation Group. Open access epidemiological data from the COVID-19 outbreak. Lancet Infect Dis 2020;20(5):534 
37 Cervino G, Fiorillo L, Spagnuolo G, et al. Interface between MTA and dental bonding agents: scanning electron microscope evaluation. J Int Soc Prev Community Dent 2017;7(1):64-68

38 Ravalli S, Musumeci G. Coronavirus outbreak in Italy: physiological benefits of home-based exercise during pandemic. J Funct Morphol Kinesiol 2020;5(2):31

39 Paoli A, Musumeci G. Elite athletes and COVID-19 lockdown: future health concerns for an entire sector. J Funct Morphol Kinesiol 2020;5(2):30

40 Odontoiatria33. Available at: http://www.odontoiatria33. it/approfondimenti/19017/coronavirus-le-raccomandazioni-per-lo-studio-odontoiatrico.html?xrtd=YSLXXASYSLYARCXACRPLSV\&fbclid=IwAR0SpjHpFZRJOheLDs-344uBk6RktHY60SiW9PCmR1_imd3zT5TmyplWBmg. Accessed 2020

41 Cicciù M, Fiorillo L, Herford AS, et al. Bioactive titanium surfaces: Interactions of eukaryotic and prokaryotic cells of nano devices applied to dental practice. Biomedicines 2019;7(1):12

42 Lo Giudice G, Cicciù M, Cervino G, Lizio A, Visco AM. Flowable resin and marginal gap on tooth third medial cavity involving enamel and radicular cementum: a SEM evaluation of two restoration techniques. Indian J Dent Res 2012;23(6):763-769

43 Cervino G, Fiorillo L, Laino L, et al. Oral health impact profile in celiac patients: analysis of recent findings in a literature review. Gastroenterol Res Pract 2018;2018:7848735

44 Cicciù M, Herford AS, Cervino G, Troiano G, Lauritano F, Laino L. Tissue fluorescence imaging (VELscope) for quick non-invasive diagnosis in oral pathology. J Craniofac Surg 2017;28(2):e112-e115
45 Lo Giudice G, Lipari F, Lizio A, Cervino G, Cicciù M. Tooth fragment reattachment technique on a pluri traumatized tooth. J Conserv Dent 2012;15(1):80-83

46 Castrogiovanni P, Trovato FM, Szychlinska MA, Nsir H, Imbesi R, Musumeci G. The importance of physical activity in osteoporosis. From the molecular pathways to the clinical evidence. Histol Histopathol 2016;31(11):1183-1194

47 Muscatello MR, Spina E, Bandelow B, Baldwin DS. Clinically relevant drug interactions in anxiety disorders. Hum Psychopharmacol 2012;27(3):239-253

48 De Stefano R. Psychological factors in dental patient care: odontophobia. Medicina (Kaunas) 2019;55(10):678

49 Zhang Y, Xu J, Li H, Cao B. A novel coronavirus (COVID-19) outbreak: A call for action. Chest 2020;157(4):e99-e101

50 Yang Y, Shang W, Rao X. Facing the COVID-19 outbreak: what should we know and what could we do? J Med Virol 2020;92(6):536-537

$51 \mathrm{Wu} \mathrm{Z,} \mathrm{McGoogan} \mathrm{JM.} \mathrm{Characteristics} \mathrm{of} \mathrm{and} \mathrm{important} \mathrm{lessons}$ from the coronavirus disease 2019 (COVID-19) outbreak in China: Summary of a report of 72314 cases from the Chinese Center for Disease Control and Prevention. JAMA 2020; 323(13):1239-1242 doi:10.1001/jama.2020.2648

$52 \mathrm{Wu} \mathrm{J}$, Wu X, Zeng W, et al. Chest CT findings in patients with coronavirus disease 2019 and its relationship with clinical features. Invest Radiol 2020;55(5):257-261

53 Tong ZD, Tang A, Li KF, et al. Potential presymptomatic transmission of SARS-CoV-2, Zhejiang Province, China, 2020. Emerg Infect Dis 2020;26(5):1052-1054 